\title{
INVESTIGATION OF THE MICROSTRUCTURE AND THERMOELECTRIC PROPERTIES OF P-TYPE BiSbTe ALLOYS BY USAGE OF DIFFERENT REVOLUTIONS PER MINUTE (RPM) DURING MECHANICAL MILLING
}

\begin{abstract}
In this work, $\mathrm{p}$-type $\mathrm{Bi}_{0.5} \mathrm{Sb}_{1.5} \mathrm{Te}_{3}$ alloys were fabricated by high-energy ball milling (MA) and spark plasma sintering. Different revolutions per minute (RPM)s were used in the MA process, and their effect on microstructure, and thermoelectric properties of p-type $\mathrm{Bi}_{0.5} \mathrm{Sb}_{1.5} \mathrm{Te}_{3}$ were systematically investigated. The crystal structure of milled powders and sintered samples were characterized using X-ray diffraction. All the powders exhibited the same morphology albeit with slight differences find at 1100 RPM conditions. A slight grain size refinement was observed on the fracture surfaces from 500 to 1100 RPM specimens. The temperature dependence of Seebeck coefficient, electrical conductivity, and power factors were measured as a function of temperature with different RPM conditions. The power factor shows almost same $\left(\sim 3.5 \mathrm{~W} / \mathrm{mK}^{2}\right.$ at RT) for all samples due to unchanged Seebeck and electrical conductivity values. The peak ZT of 1.07 at $375 \mathrm{~K}$ is obtained for $1100 \mathrm{RPM}$ specimen due to low thermal conductivity.

Keywords: $\mathrm{Bi}_{0.5} \mathrm{Sb}_{1.5} \mathrm{Te}_{3}$ alloys, Mechanical alloying, Spark plasma sintering, Thermoelectric properties
\end{abstract}

\section{Introduction}

Thermoelectric devices have a vital role in the future needs of energy consumption, are basically used for power generation or refrigeration applications. The energy conversion is explicitly depending on the efficiency factor, which is defined by a dimensionless figure of merit, $\mathrm{ZT}=\alpha^{2} \sigma T / \kappa$, where $\alpha, \sigma, \kappa, T$ are the Seebeck coefficient, electrical conductivity, thermal conductivity, and absolute temperature respectively [1]. It is evident that ascribed parameters are interdependent with each other and can be expressed as a function of carrier density. Therefore, decoupling of these parameters are extremely challenging [2]. Recently, researchers are developing a new approach such as low dimensional structures, and bulk nanostructuring approaches for optimizing these parameters $[2,3]$.

Bismuth telluride $\left(\mathrm{Bi}_{2} \mathrm{Te}_{3}\right)$-based alloys are used for thermoelectric devices due to their outstanding energy conversion at room temperature. Rama et al eminently improved the thermoelectric figure of merit, ZT of 2.4 in $\mathrm{Bi}_{2} \mathrm{Te}_{3} / \mathrm{Sb}_{2} \mathrm{Te}_{3}$ superlattice structures by extremely reducing thermal conductivity via phonon blocking mechanism [4]. However, the low dimensional methods are difficult for large scale device fabrication and expensive way. W. Xie et al. studied that the unique $\mathrm{Bi}_{2} \mathrm{Te}_{3}$ nanostructures can eminently reduce thermal conductivity which can contributed the high ZT of 1.56 by melt spun \& hot pressing process [5]. In other parts, ball milling offers ultrafine powders, which is very important factor to decide the grain size in the sintered bulks. Recently, Poudel et al. achieved a peak ZT of
1.4 in p-type Bi-Te based alloys by ball milling and hot pressing, which is mainly due to the reduction in thermal conductivity [6]. However, the fabrication of such ultrafine powders is strictly depending on the ball milling parameters (ball size, revolutions per minute (RPM), ball to powder ratio (BPR) etc.) which can restrict the particle size, shape and so on [7]. In addition, spark plasma sintering is an effective and cutting edge low sintering temperature technique which can restrict the grain growth during sintering [8]. In our previous report, we studied the effect of milling time, and ball sizes on the powder morphology, microstructure and thermoelectric properties of p-type $\mathrm{Bi}_{2} \mathrm{Te}_{3}$ based systems $[9,10]$. However, no reports are studied on the revolutions per minute (RPM) on p-type $\mathrm{Bi}_{2} \mathrm{Te}_{3}$ thermoelectric materials during the ball milling.

In this research, $\mathrm{p}$-type $\mathrm{Bi}_{0.5} \mathrm{Sb}_{1.5} \mathrm{Te}_{3}$ fine powders are fabricated by ball milling from commercially available micron size powders. Subsequently, the ball milled fine powders are sintered by SPS at $400^{\circ} \mathrm{C}$ for $10 \mathrm{~min}$. Here, we report on the effect of revolutions per minute (RPM) on powder morphology, microstructures, and thermoelectric properties are investigated.

\section{Experimental}

In this research, gas atomized p-type $\mathrm{Bi}_{0.5} \mathrm{Sb}_{1.5} \mathrm{Te}_{3}$ powders (size $<200 \mu \mathrm{m}$ ) was used for mechanical milling. The nano to submicron order powders were fabricated by planetary ball miller (P100) in argon atmosphere. The revolutions per minutes (RPM)

\footnotetext{
DIVISION OF ADVANCED MATERIALS ENGINEERING AND INSTITUTE FOR RARE METALS, KONGJU NATIONAL UNIVERSITY, CHEONAN, CHUNGNAM, 330-717, KOREA 


\section{Results and discussion}

have been changed while the ball to powder ratio were kept at 15:1. Subsequently, the ball milled powders were consolidated by spark plasma sintering under an axial compressive stress of $50 \mathrm{MPa}$ at $673 \mathrm{~K}$.

The crystal phase of the powders and sintered samples was analyzed with X-ray diffraction (Rigaku Miniflex diffractometer) using $\mathrm{CuK}_{\alpha}$ radiation. The morphology of the ball milled powders and fracture surface of sintered samples were analyzed by scanning electron microscopy (SEM- MIRA LMH II (TESKAN), Czech Republic). The oxygen contamination of the milled powders was determined by Eltra ONH-2000 Oxygen/Nitrogen/ Hydrogen determinator. The relative density $(d)$ of the samples were measured from the Archimedes principle.

The temperature dependence of the thermoelectric properties such as Seebeck coefficient and electrical conductivity and measured by the thermoelectric power (Seepel, TEP-1000) measurement system. Four probe method was used for the carrier concentration and hall mobility measurements. The power factor was calculated from the multiply of the square of the Seebeck coefficient and electrical conductivity. The thermal diffusivity, $D$ was measured using laser flash method (Netzsch, LFA). The specific heat, $C_{p}$ was measured using Perken thermal analyzer. Thermal conductivity, $\kappa$ was calculated using the equation, $\kappa=D C_{p} d$. The figure of merit, ZT is calculated using power factor and thermal conductivity.
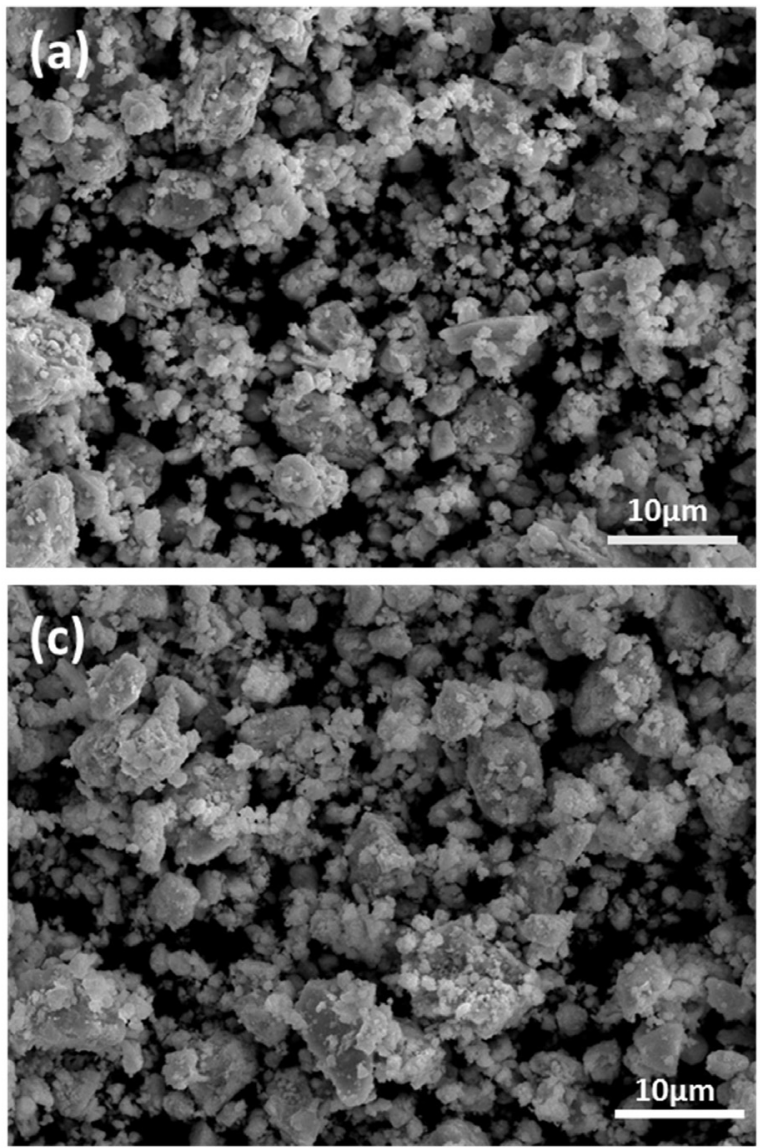
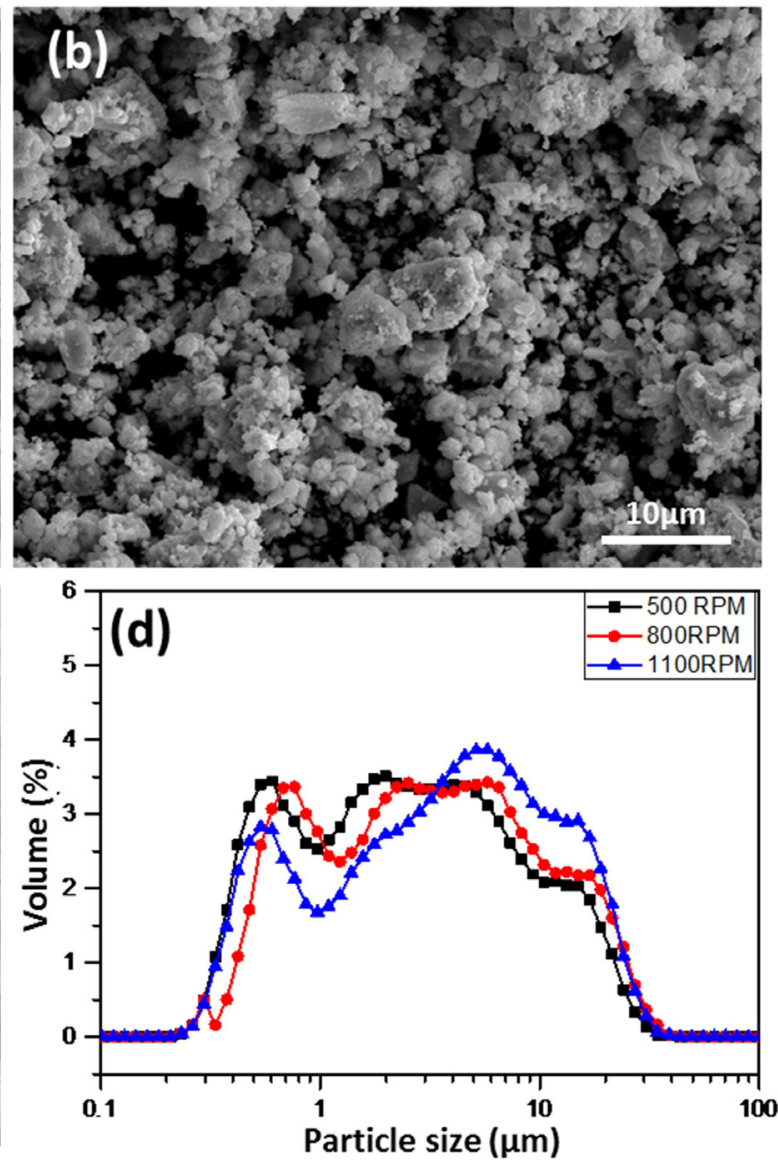

Fig. 1. Morphology of p-type $\mathrm{Bi}_{0.5} \mathrm{Sb}_{1.5} \mathrm{Te}_{3}$ powders using different RPM (revolutions per minute) during MA (a) 500 , (b) 800 , (c) $1100 \mathrm{RPMs}$ and (d) powder size analysis of MA-ed powders 
proved mechanical properties. The XRD pattern of $\mathrm{Bi}_{0.5} \mathrm{Sb}_{1.5} \mathrm{Te}_{3}$ powders and sintered bulks are shown in Figure 2. The powders and bulk samples are well indexed to the $\mathrm{Bi}_{0.5} \mathrm{Sb}_{1.5} \mathrm{Te}_{3}$ (JCPDS \# 49-1713) with rhombohedral crystal structure [12]. It is evident that the all basal and non-basal planes have same intensity and two theta positions, indicating that no structural changes and no preferred orientation in any special direction. Moreover, no other impurity peaks have been detected in the XRD analysis.
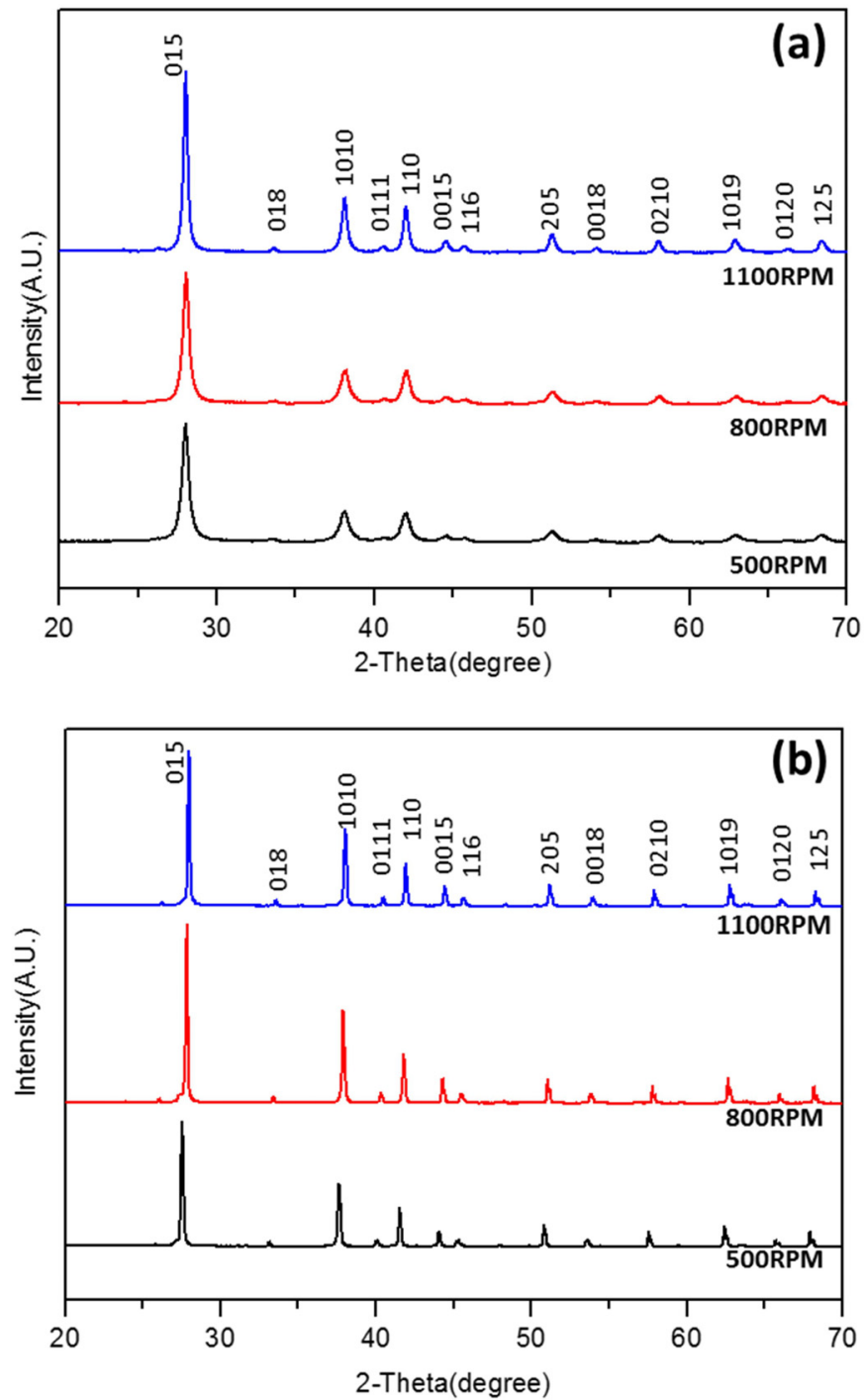

Fig. 2. XRD analysis of (a) MA-ed powders and (b) SPS-ed bulks of p-type $\mathrm{Bi}_{0.5} \mathrm{Sb}_{1.5} \mathrm{Te}_{3}$ alloys

The fracture surface of $\mathrm{Bi}_{0.5} \mathrm{Sb}_{1.5} \mathrm{Te}_{3}$ sintered bulks with different RPMs are shown in Figure 3. The grains are appeared to be fine with laminar structures, are distributed in entire fracture surfaces for all samples. Also, there are no pores have been observed on the fracture surfaces which is well consistence with the relative density (shown in Table 1). There is slight grain size refinement has observed from 500 to 1100 RPM. However, all sintered bulks show that almost random grain orientation which is good agreement with XRD analysis (See Figure 2). This might affect the transport of carrier in the matrix which would severely influence the thermoelectric properties [13].
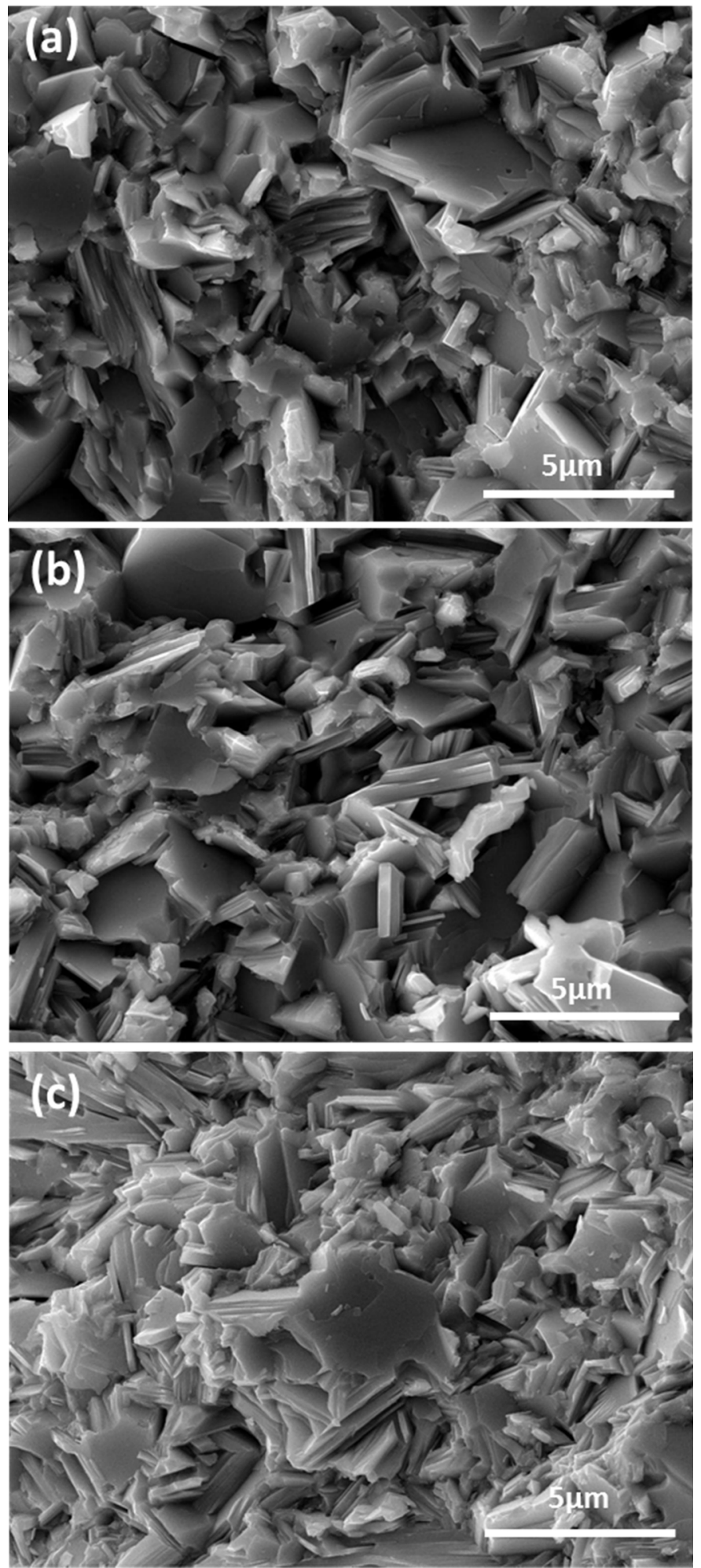

Fig. 3. Fracture surface analysis of p-type $\mathrm{Bi}_{0.5} \mathrm{Sb}_{1.5} \mathrm{Te}_{3}$ bulks using different RPMs during MA (a) 500, (b) 800, and (c) 1100 RPM

Figure 4 shows the temperature dependence of Seebeck coefficient $(\alpha)$, electrical conductivity $(\sigma)$, and power factor for $\mathrm{Bi}_{0.5} \mathrm{Sb}_{1.5} \mathrm{Te}_{3}$ samples with the different RPMs used during ball milling. All samples in Figure 4a shows the positive Seebeck coefficient indicating p-type semiconducting behavior [14]. The Seebeck coefficient is linearly increased with temperature. It is evident that the Seebeck coefficient show almost same values 
TABLE 1

Oxygen content, relative density, carrier concentration and hall mobility of p-type $\mathrm{Bi}_{0.5} \mathrm{Sb}_{1.5} \mathrm{Te}_{3}$ alloys by mechanical milling

\begin{tabular}{|c|c|c|c|c|}
\hline \hline $\begin{array}{c}\text { Milling } \\
\text { Time }\end{array}$ & $\begin{array}{c}\text { Oxygen } \\
\text { content } \\
\mathbf{( \% )}\end{array}$ & $\begin{array}{c}\text { Relative } \\
\text { density } \\
\mathbf{( \% )}\end{array}$ & $\begin{array}{c}\text { Carrier } \\
\text { concentration, } \\
\left.\boldsymbol{n} \mathbf{( 1 0}^{\mathbf{1 9}} / \mathbf{c m}^{\mathbf{3}}\right)\end{array}$ & $\begin{array}{c}\text { Hall mobility, } \\
\left.\boldsymbol{\mu} \mathbf{( c m}^{\mathbf{2}} \mathbf{V s}\right)\end{array}$ \\
\hline $\mathbf{5 0 0}$ & 0.234 & 99.8 & 2.66 & 256 \\
\hline $\mathbf{8 0 0}$ & 0.222 & 99.9 & 2.6 & 263 \\
\hline $\mathbf{1 1 0 0}$ & 0.313 & 99.8 & 2.34 & 289 \\
\hline
\end{tabular}

for all sintered samples regardless of different RPMs used in the present study. In general, the Seebeck coefficient is more sensitive to carrier concentration $\left(n_{c}\right)$, and can be expressed as [15]:

$$
\alpha=\gamma-\ln n_{c}
$$

where $\gamma$ is the scattering parameter. The measured carrier concentration and hall mobility is shown in Table 1 . The carrier concentration is measured about $2.66 \times 10^{19} \mathrm{~cm}^{-3}$ for $500 \mathrm{RPM}$ sample which is almost similar to the 800RPM bulks. However, slight decrease in carrier concentration has observed in 1100 RPM due to the small increase in oxygen content (see in Table 1). As a result, a slight increase in hall mobility is observed for 1100 RPM. However, the magnitude of carrier concentration, and mobility are almost same, so one can expect the same scattering parameter. Therefore, the Seebeck coefficient is obviously same for all samples regardless of different RPMs used in the present study.

Figure $4 \mathrm{~b}$ shows the temperature dependence of the electrical conductivity, $\sigma$ for the p-type $\mathrm{Bi}_{0.5} \mathrm{Sb}_{1.5} \mathrm{Te}_{3}$ sintered samples. It is seen that the electrical conductivity is decreases with increasing measurement temperature, indicating degenerate semiconducting behavior. The maximum electrical conductivity is measured about $\sim 1000 \Omega^{-1} \mathrm{~cm}^{-1}$ for all samples regardless of different RPMs used in the present study. The electrical conductivity, $\sigma$ can be expressed in terms of carrier concentration $\left(n_{c}\right)$ and mobility $(\mu)$ is given by [15],

$$
\sigma=n e \mu
$$

where $e$ is the charge of the carrier. The carrier concentration $\left(n_{c}\right)$ and mobility $(\mu)$ in Table 1 are almost similar with the different RPMs during the ball milling. These unchanged transport properties such as carrier concentration $\left(n_{c}\right)$ and mobility $(\mu)$ resulting in almost same electrical conductivity for sintered samples.

The temperature dependence of power factor for p-type $\mathrm{Bi}_{0.5} \mathrm{Sb}_{1.5} \mathrm{Te}_{3}$ sintered samples are shown in Figure $4 \mathrm{c}$. The power factor values are calculated from the Seebeck coefficient and electrical conductivity. The tendency of the power factor values are decreases with increasing temperature, which is similar trend with electrical conductivity. Moreover, the power factor is obtained almost same for the whole temperature range from 300 to $400 \mathrm{~K}$ owing to the similar Seebeck coefficient and electrical conductivity for all samples regardless of different RPMs conditions used in the present work.

The temperature dependence of thermal conductivity, $\kappa$ of p-type $\mathrm{Bi}_{0.5} \mathrm{Sb}_{1.5} \mathrm{Te}_{3}$ samples are shown in Fig. 5a. It is evident
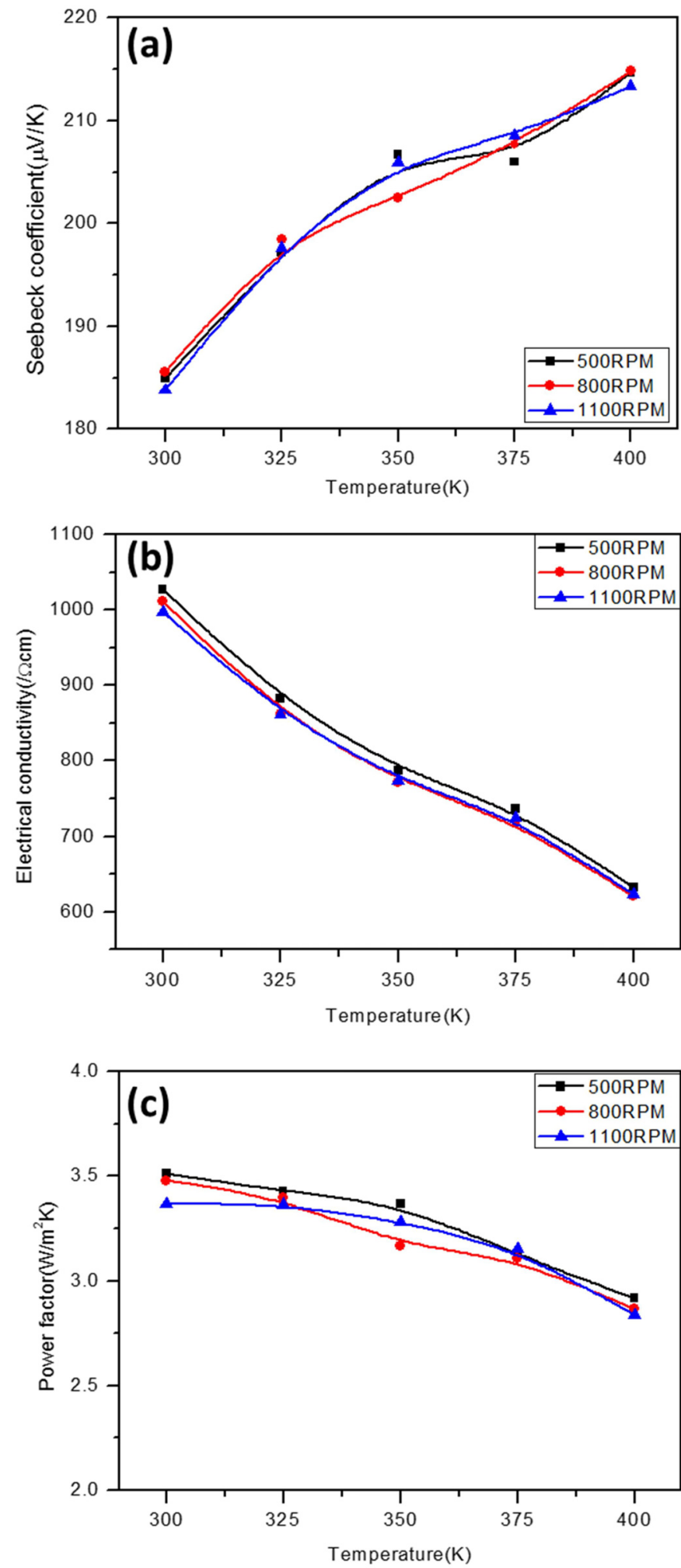

Fig. 4. Temperature dependence of (a) Seebeck coefficient, (b) electrical conductivity, and (c) power factor for p-type $\mathrm{Bi}_{0.5} \mathrm{Sb}_{1.5} \mathrm{Te}_{3}$ bulks using different RPMs during MA

that the $\mathrm{Bi}_{0.5} \mathrm{Sb}_{1.5} \mathrm{Te}_{3}$ samples exhibit $\kappa$ values between 1.2 to 1.4 for all temperature ranges. The slight variation in $\kappa$ values among the samples are attributed to the variation in electrical conductivity values. The thermoelectric figure of merit, ZT of p-type $\mathrm{Bi}_{0.5} \mathrm{Sb}_{1.5} \mathrm{Te}_{3}$ samples are shown in Fig. 5b. The ZT values are increases with increasing temperature attributed to the 
increasing behavior of Seebeck coefficient (shown in Fig. 4a). The peak ZT values of samples are $0.97,0.92$, and 1.07 for 500 RPM, 800 RPM, and 1100 RPM at $375 \mathrm{~K}$, respectively. The higher ZT values for 1100 RPM are due to the lower thermal conductivity. The present work shows the improved figure of merit $(\mathrm{ZT}=1.07$ at $300 \mathrm{~K})$ than other p-type $\mathrm{Bi}$-Sb based alloys by different powder metallurgy methods including gas atomization [16], melt spinning [17], and bulk mechanical alloying [18].
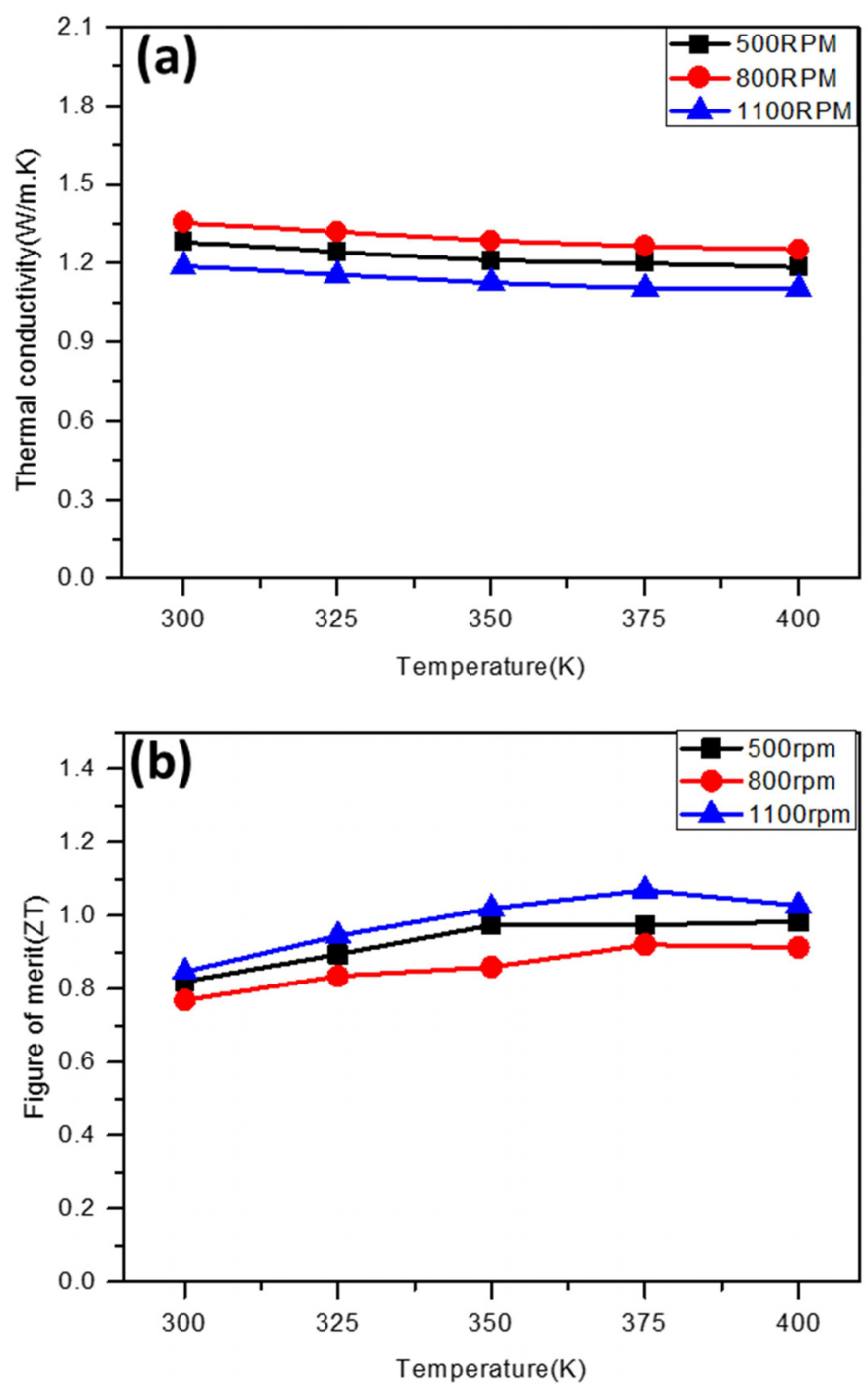

Fig. 5. Temperature dependence of (a) thermal conductivity, and (b) figure of merit for $\mathrm{p}$-type $\mathrm{Bi}_{0.5} \mathrm{Sb}_{1.5} \mathrm{Te}_{3}$ bulks using different RPMs during MA

\section{Conclusions}

In summary, p-type $\mathrm{Bi}_{0.5} \mathrm{Sb}_{1.5} \mathrm{Te}_{3}$ fine powders were successfully fabricated by high energy ball milling, and subsequently sintered using spark plasma sintering. The ball milled powders show fine powder and bulks with irregular shape regardless of different RPMs conditions used during the ball milling. The XRD pattern of powders and bulks identify the single phase of
$\mathrm{Bi}_{0.5} \mathrm{Sb}_{1.5} \mathrm{Te}_{3}$ with rhombohedral crystal structure. All most full relative density $(100 \%)$ is obtained for sintered bulks regard less of RPM conditions. The temperature dependence of Seebeck coefficient, electrical conductivity, and power factors were investigated, and the results revealed that the different RPMs used in the HRBM is negligible in p-type $\mathrm{Bi}_{0.5} \mathrm{Sb}_{1.5} \mathrm{Te}_{3}$ alloys. The power factor shows almost same $\left(\sim 3.5 \mathrm{~W} / \mathrm{mK}^{2}\right.$ at RT) for all samples. The thermoelectric figure of merit was calculated using measured thermal conductivity, and power factor. The peak ZT of 1.07 at $375 \mathrm{~K}$ is achieved for $1100 \mathrm{RPM}$ due to the exhibiting low thermal conductivity.

\section{Acknowledgments}

This work was supported by the Korea Institute of Energy Technology Evaluation and Planning (KETEP) grant funded by the Korea government Ministry of Knowledge Economy (No. 20115010100020).

\section{REFERENCES}

[1] G.J. Snyder, E.S. Toberer, Nat. Mater. 7, 105 (2008).

[2] T.M. Tritt, H. Bottner, L.D. Chen, MRS Bulletin 33, 366 (2008).

[3] L.M. Goncalves, C. Couto, P. Alpuim, D.M. Rowe, J.H. Correia, Mater. Research. Forum, 156, 541-516 (2006).

[4] R. Venkatasubramanian, E. Siivola, T. Colpitts, B. O'Quinn, Nature 413, 597 (2001).

[5] W. Xie, J. He, H.J. Kang, X. Tang, S. Zhu, M. Laver, S. Wang, J.R.D. Copley, C.M. Brown, Q. Zhang, T.M. Tritt, Nano Lett. 10, 3283-3289 (2010).

[6] B. Poudel, Q. Hao, Y. Ma, Y. Lan, A. Minnich, B. Yu, X. Yan, D. Wang, A. Muto, D. Vashaee, X. Chen, J. Liu, M.S. Dresselhaus, G. Chen, Z. Ren, Science 320, 634 (2008).

[7] C. Suryanarayana, Mater. Science 46, 1 (2013).

[8] C.-H. Lee, M.F. Kilicaslan, B. Madavali, S.-J. Hong, Res. Chem. Intermed. 40, 2543 (2014).

[9] M.L. Lwin, S.M Yoon, B. Madavali, C.H. Lee, S.J. Hong, J. Korean Powder Metall. Inst. 23, 120 (2016).

[10] B. Madavali, S.J. Hong, J. Electron. Mater. 45, 6059 (2016).

[11] H.S. Kim, B. Madavali, T.J. Eom, C.M. Kim, J.M. Koo, T.H. Lee, S.J. Hong, Arch. Metall. Mater. 60, 1235 (2015).

[12] Y.H. Yeo, T.S. Oh, Mater. Res. Bull. 58, 54 (2014).

[13] S.J. Hong, B.S. Chun, Mater. Res. Bull. 38, 599 (2003).

[14] K.T. Kim, T.S. Lim, G.H. Ha, Reviews on Adv. Mater. Sci. 28, 196 (2011).

[15] S.T. Han, P. Rimal, C.H. Lee, H.S. Kim, Y. Sohn, S.J. Hong, Intermetallics 78, 42 (2016).

[16] C.D. Moon, T.S. Kim, J. Alloys. Compd. 536S, S559 (2012).

[17] T.S. Kim, B.S. Chun, J.K. Lee, H G. Jung, J. Alloys. Compd. 710, 434 (2007).

[18] J. Yang, T. Aizawa, A. Yamamoto, T. Ohta, Mater. Chem. Phys. 70, 90 (2001). 